\title{
THE DEVELOPMENT OF TECHNOLOGY FOR TOPICAL APPLICATION OF XENON AS PART OF AN EXTERNAL AGENT AND ITS EFFECT ON RAT SKIN WOUND HEALING
}

\author{
Evgeny Petrov ${ }^{\mathrm{a}}$, Vladimir Kozik, Alexander Verkhovskiy \\ National Research Tomsk State University, 634050, Tomsk, Russia
}

\begin{abstract}
We have developed an agent for external use to deliver xenon into the skin. Using the model of skin wound we have studied the effect of xenon on the process of wound healing in rats. It has been shown that the application of xenon-containing cream on wound surface significantly accelerates the healing process as compared to control animals where cream without xenon has been applied.
\end{abstract}

\section{Introduction}

Biological effects of xenon mainly studied in the field of anesthesiology and therapy $[1,2]$. In previous studies with xenon inhalation have shown that xenon has neuroprotective [3-6], analgetic [7-9], antihypoxic [10] cardioprotective activity [11], exhibits anti-stress and adaptation effect [12], works as cryoprotecting agent in frozen cell cultures [13]. Based on the fact of xenon high solubility in fats and to a lesser extent in water [14, 15], we have developed a technology for producing liquid media with different compositions xenon [16]. Given that the application of liquid media with xenon skin observed its transdermal diffusion [17], it is reasonable to assume that xenon can affect the dynamics of healing, since it is in the area of the wound surface the metabolism is more intense than in the intact adjacent areas. To create a high local concentration of xenon on the skin surface, it is necessary to use agents (creams, ointments, etc.) with high lipophilic content. It is also necessary to take into account the convenience of using such an external agent. The most appropriate means such, in our opinion, would be an emulsion with a high content of lipophilic components. On the basis of such emulsions with a high content of lipophilic substances external agents saturated with xenon can be developed in various forms. In this paper we investigate the effect of topical application xenon on the process of healing of skin lesions (excision wound).

\footnotetext{
${ }^{\text {a }}$ Corresponding author:alverkhovniy@mail.ru
} 


\section{Materials and methods}

Experiment on animals were conducted in accordance with WMA Declaration of Helsinki and within a frame of Russian legislation for the use of animals in biomedical research. Work has been done on 30 mixed white male rats weighing 150-180g. All animals were divided into 3 groups of 10. In all animals under light ether anesthesia scalp was removed and in the central region of the upper third of the back full-thickness skin excisions were made. Wounds had a circular shape with a diameter of $6 \mathrm{~mm}$ (Figure 1). The first group (control) after excision of skin is not subjected to any stress. In the second group of animals after skin excision on the wound surface $0.2-0.3 \mathrm{ml}$ of cream was applied without xenon every morning and evening. In the third (experimental) group after excision of skin daily (morning and evening) was applied xenon-containing cream. Patches of wounded skin were taken for a histological study at 7 th and 15 th day after wounding.

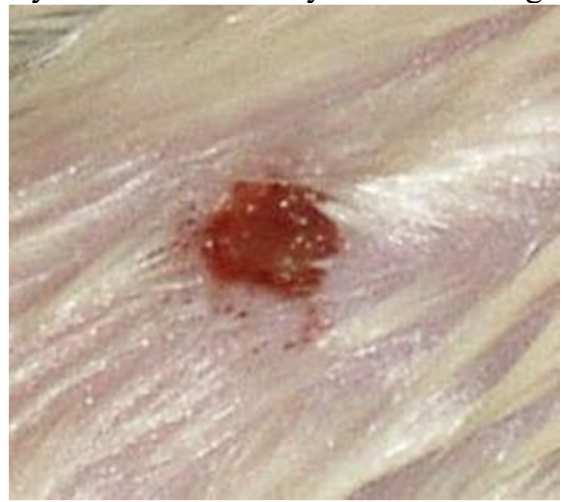

Figure 1. Prepared wound surface (magn. $\left.10^{\mathrm{x}}\right)$.

The cream for external application was prepared according to the formulation, which includes: olive oil, water, xenon, thickener / emulsifier DC RM 2051 (Sodium polyacrylate, dimethicone, cyclopentasiloxane, trideceth-6, PEG / PPG-18/18 Dimethicone, Dow Corning Corporation, USA), Euxyl 712 preservative (sodium benzoate, potassium sorbate, Shulke \& Mayer GmbH, Germany) at room temperature. Using DC RM 2051 allows adding a large amount of oil $(40 \%)$ in the composition of the cream. Before mixing and homogenizing the components xenon was dissolved in olive oil at ratio $200 \mathrm{~cm}^{3} / 100 \mathrm{ml}$. Immediately after preparation, the resulting emulsion was poured into a $10 \mathrm{ml}$ sealed containers.

\section{Results and discussion}

Histology of wounded and intact skin on day $1^{\text {st }}$ is shown in Figure 2. Healing of the wound area occurred in all rats by primary intention with scab formation of characteristic dark brown color. The animals of the first group macroscopically observed a slight decrease in size of the wound for the first 7 days (Figure 3). Morphologically it marked the beginning of the epithelium creeping on wound surface. On day 15 the animals of this group macroscopically observed wound healing with scab rejection (Figure 4). On histological preparations the restoration of the epithelium was observed, however, elements of the dermis of the skin and appendages are underdeveloped. 


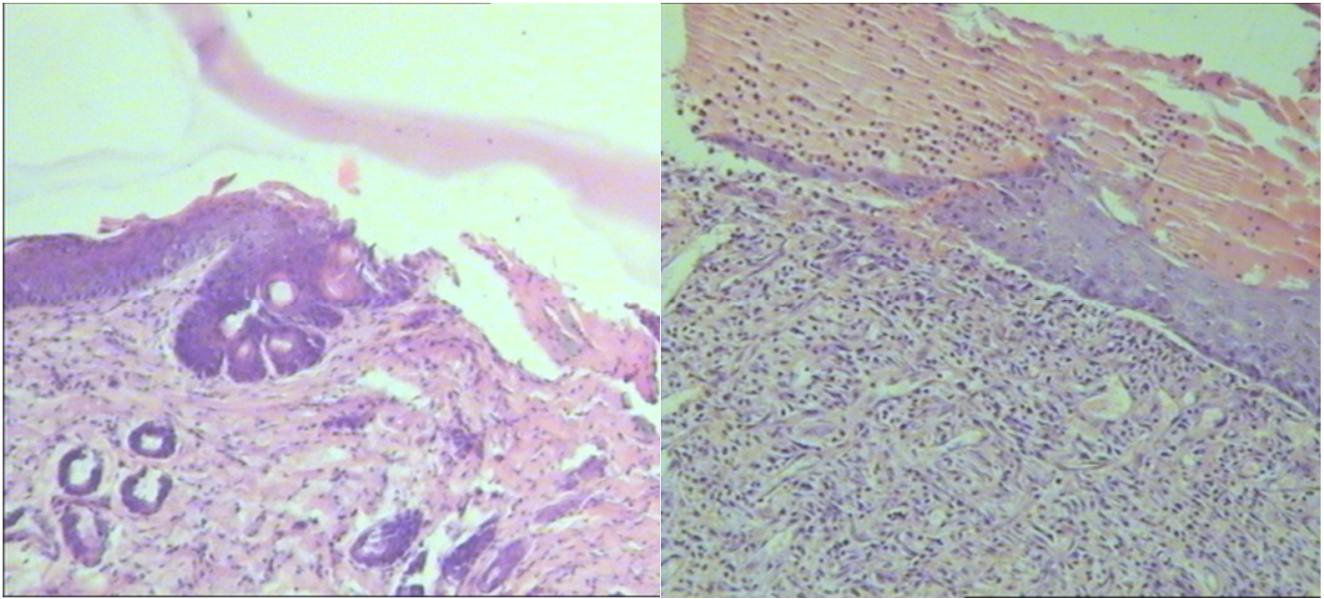

Figure 2. The border of normal skin and fullthickness wounds. (Hematoxylin-eosin staining, magn. $\left.120^{\mathrm{x}}\right)$.
Figure 3. Creeping epithelium after 7 days of the experiment. (Hematoxylin-eosin staining, magn. $\left.120^{\mathrm{x}}\right)$.

In the second group of rats, the regeneration picture (macro and microscopic) was not significantly different and correspond to the control group. Scab virtually disappeared for $9^{\text {th }}-10^{\text {th }}$ day. In the third group on day 7 the wound healing was more pronounced. Wound size was reduced to about $2 / 3$, scab almost disappeared. There was a rapid restoration of hair in the area of the wound. On day 15 the epidermis structure was close to normal, also observed active regeneration of dermis and appendages of skin due to proliferation of dermal cells, vascular neoplasm, and restoration of the structure of sebaceous glands (Figure 5).

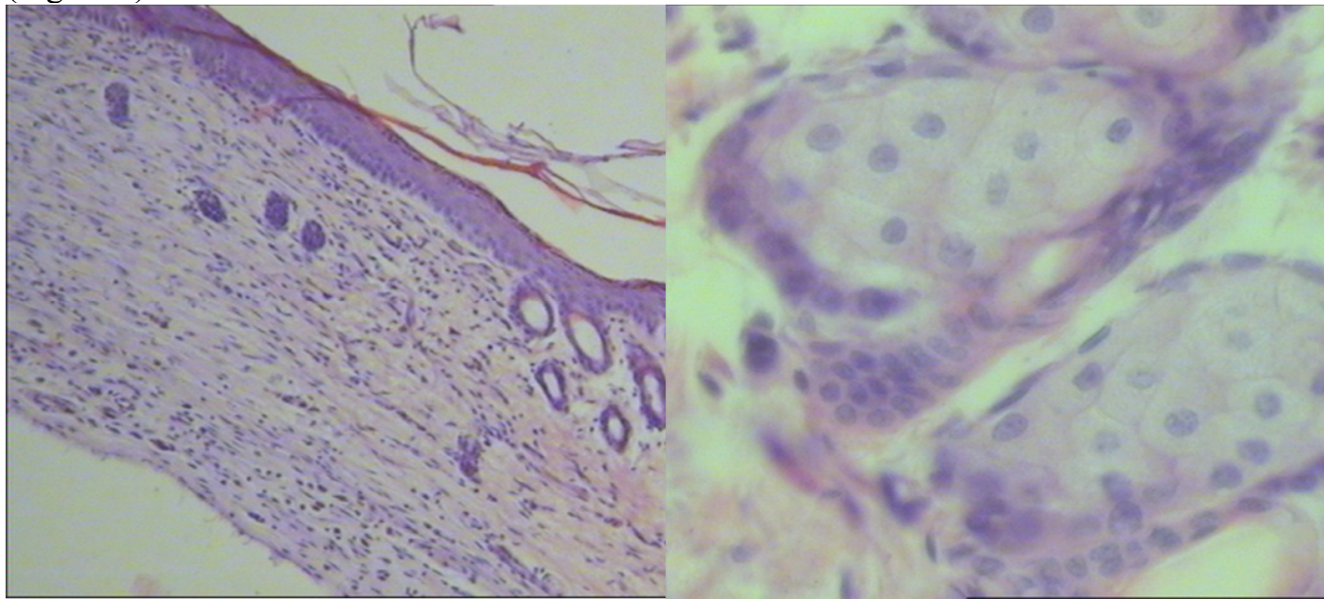

Figure 4. Skin recovery on 15 day of experiment. (Hematoxylin-eosin staining, magn. $\left.120^{\mathrm{x}}\right)$.
Figure 5. The normal structure of the sebaceous glands on day 15 of the experiment. (Hematoxylin-eosin staining, magn. $400^{x}$ ).

In this experimental work we have demonstrated the efficacy of xenon present in a cream applied to the wound surface, to enhance the skin regeneration process. Furthermore, it has been observed more rapid recovery of hair. The cream formula used in this study does not include active components used in the treatment of external skin lesions, thus skin wound healing caused directly by xenon dissolved in applied cream. Proposed agents for external use are based on sole mechanism of action - lipophilic vesicles carrying xenon in 
high concentrations of xenon are readily absorbed onto the surface of epidermis as compared with other components of an external agent (Figure 6).

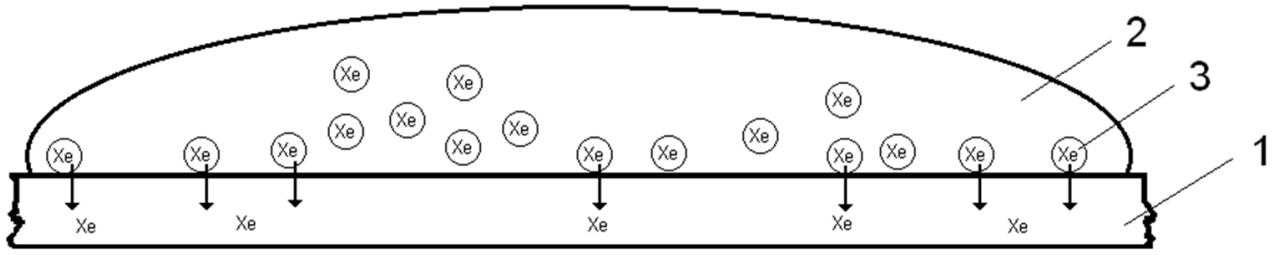

Figure 6. The mechanism of action of xenon-containing external agent.

On epidermis (1) is applied a cream (emulsion), (2), comprising a lipophilic vesicles (3) with a high content of xenon. Absorbed in the epidermis vesicles provide conditions for an effective diffusion of xenon in deeper layers of skin.

\section{Conclusions}

The xenon-containing emulsion we have developed may serve as a prototype for other external agents in various forms (cream, gel, ointment, etc.). Furthermore, the xenon may be added to already known formulations of means for external use, containing active components, including the form of a patch. Thus, we believe that obtained data can be used in the development of external means used for healing of skin lesions of various origins.

\section{Acknowledgment}

The paper was written as part of the research project No. 8.2.31.2015, carried out with the support of the Program "Research Foundation of Tomsk State University named after D.I. Mendeleev" in 2015 - 2016.

\section{References}

[1] S.C. Cullen, E.G. Gross, Science 113, $580 \quad$ (1951) doi:10.1126/science.113.2942.580

[2] B. Lachmann, S. Armbruster, W. Schairer, M. Landstra, A. Trouwborst, G.J. Van Daal, et al., Lancet 335, 1413 (1990)

[3] E. Esencan, S. Yuksel, Y.B. Tosun, A. Robinot, I. Solaroglu, J.H. Zhang, Med. Gas Res. 3,4 (2013) doi:10.1186/2045-9912-3-4

[4] J. Lavaur, M. Lemaire, J. Pype, D. Le Nogue, E.C. Hirsch, P.P. Michel, Cell Death Dis. 7, e2182 (2016) doi:10.1038/cddis.2016.86

[5] H.M. Homi, N. Yokoo, D. Ma, D.S. Warner, N.P. Franks, M. Maze, et al., Anesthesiology 99, 876 (2003) doi: 10.1097/00000542-200310000-00020

[6] H.N. David, B. Haelewyn, C. Rouillon, M. Lecoq, L. Chazalviel, G. Apiou, et al., FASEB J. 22,1275 (2008) doi:10.1096/fj.07-9420com

[7] M. Giacalone, A. Abramo, F. Giunta, F. Forfori, Clin. J. Pain. 29(7), 639 (2013) doi:10.1097/AJP.0b013e31826b12f5

[8] T. Fukuda, C. Nishimoto, S. Hisano, M. Miyabe, H. Toyooka, Anesth. Analg. 95, 1300 (2002)

[9] L. Yang, C. a Tulk, D.D. Klug, I.L. Moudrakovski, C.I. Ratcliffe, J. a Ripmeester, et al., Proceedings of the National Academy of Sciences of the United States of America 106, 6060 (2009) doi:10.1073/pnas.0809342106 
[10] V.N. Ananev, Receptor mechanisms of neutral gas in oxygen consumption, Fundam. Res. (11),11 (2013)

[11] W. Liu, Y. Liu, H. Chen, K. Liu, H. Tao, X. Sun, Med. Gas Res. 3, 3 (2013) doi:10.1186/2045-9912-3-3

[12] V. Potievskaya, N. Stryapko, T. Sazontova, I. Vdovina, Y. Archipenko, I. Molchanov, Eur. J. Anaesthesiol. 31, 159 (2014)

[13] K. Seino, K. Sato, M. Ujihira, IEEE Eng. Med. Biol. 22, 1989 (2008) http://embc.embs.org/files/2013/3025_FI.pdf

[14] E. Overton, Studien über die Narkose, zurgleich eing Bertrag zur allgemeinen Pharmakologie (Verlag Gustav Fischer, Jena, 1901)

[15] H. Meyer, Arch. Für Exp. Pathol. Und Pharmakologie 42, 109 (1899) doi:10.1007/BF01834479

[16] A. Verkhovsky, A device for gas saturation of liquid media Patent № 156912, 2015

[17] A.Y. Verkhovskiy, D.N. Atochin, S.N. Udintsev, S.I. Tverdokhlebov, Y. Anfinogenova, V.Y. Serebrov, Dermatology Asp. 3, 2 (2015) doi:10.7243/20535309-3-2 